\title{
Evaluation of soil moisture estimated from IASI measurements
}

\author{
Daniel K. Zhou,* Allen M. Larar, and Xu Liu \\ Science Directorate, NASA Langley Research Center, Hampton, VA, USA
}

\begin{abstract}
ABSTRCT
A simple yet effective scheme to estimate volumetric soil moisture (VSM) using infrared (IR) land surface emissivity retrieved from satellite IR spectral radiance measurements was recently developed, assuming other parameters impacting the radiative transfer (e.g., temperature, vegetation coverage, and surface roughness) are known for an acceptable time and space reference location. This scheme was applied to a decade of global IR emissivity data retrieved from MetOp-A Infrared Atmospheric Sounding Interferometer measurements. Global datasets of monthlymean $0.25^{\circ}$ spatial-grid VSM, estimated from IR emissivity data (denoted as IR-VSM), are assembled to compare with those routinely provided by satellite microwave (MW) multi-sensor measurements (obtained from the ESA CCI website). The IR-VSM dataset is used to demonstrate its spatial variations as well as seasonal-cycles and inter-annual variability which are spatially coherent and consistent with that from MW measurements. Herein we report on some initial evaluation of the IR-VSM absolute values using in-situ measurements available from the Soil Climate Analysis Network of the USDA website. From the 114 ground station locations, we infer a mean bias between monthly-mean in-situ VSM and satellite derived IR-VSM of $0.005\left(\mathrm{~m}^{3} / \mathrm{m}^{3}\right)$ over the past decade, despite the differences between physical measurements. The absolute accuracy of IR-VSM is also evaluated using an independent source of soil moisture measurements.
\end{abstract}

Keywords: Satellite, remote sensing, retrieval, soil moisture.

\section{INTRODUCTION}

Land surface thermodynamic parameters are significant in Earth system science applications and provide linkage to the energy balance between the land surface and atmosphere. These land surface parameters of skin temperature, emissivity, and soil moisture, together with atmospheric thermodynamic parameters, are critical to scientific research concerned with the hydrologic cycle, weather, and climate [1-3]. Significant efforts have been devoted to the observation, modeling, and understanding of these parameters [4,5]. Satellite-based microwave (MW) sensors have been developed and deployed to derive global soil moisture since 1978 [6,7]. Global volumetric soil moisture (VSM) products are routinely derived from satellite microwave sensors. However, efforts have been made in estimating soil moisture from thermal infrared (TIR) measurements as well for many decades [6,8,9]. Previous studies have also recognized that the land surface emissivity retrieved from infrared (IR) radiance measurements contains land moisture content information [10-13]. Such land surface water content information (i.e., soil moisture) is present within IR radiance measurements from the polar-orbiting environmental satellite advanced atmospheric sounding sensors such as the MetOp Interferometer Atmospheric Sounding Instrument (IASI) [14-16].

An investigation on the relationship between IR-VSM and infrared land surface emissivity from a global perspective as inferred from advanced sounder satellite data of IASI has been previously reported [17]. That study demonstrated that the land surface emissivity retrieved from IR hyperspectral measurements contains soil moisture content information. VSM was estimated using infrared land surface emissivity and climatological pseudo dry-emissivity. The climatological pseudo dry-emissivity was generated by using VSM climatology routinely provided by satellite microwave (MW) multi-sensor measurements (denoted as MW-VSM, obtained from the ESA CCI website) [7] together with IASI IR emissivity climatology [18]. IR-VSM variation was demonstrated and consistent with MWVSM using an 8-year period of overlapping satellite data from MW and IR observations. It was pointed out that the climatological data of MW-VSM and IR emissivity were used; and climatological pseudo dry-emissivity controls

*Email: daniel.k.zhou@nasa.gov; Tel: 757-864-5663; Fax: 757-864-4343 
absolute scaling of the IR-VSM to encounter MW-VSM, the same dataset used for pseudo dry-emissivity climatology. However, it still allows IR-VSM to characterize geophysical field spatial and temporal variability. A positive agreement was shown to exist between IR- and MW-VSM [17].

As a follow up study to our recent publication [17], here we use ground in-situ measurements available from the Soil Climate Analysis Network (SCAN) (https://www.wcc.nrcs.usda.gov/scan/) [19] to evaluate the absolute value of IRVSM. Ground in-situ soil moisture measurements are commonly used to evaluate satellite observations [4,7,20,21]. In this report, a brief description on the relationship between IR-VSM and emissivity is given in Section 2. Monthlymean $0.25^{\circ}$ latitude-longitude gridded VSM datasets showing seasonal-cycles and inter-annual variations are presented in Section 3 to show a positive agreement on field spatial and temporal variability between IR- and MWVSM. Initial evaluation and discussion on IR-VSM absolute accuracy using ground in-situ soil moisture measurements of the SCAN network are also presented in Section 3. Conclusions are given in Section 4.

\section{SOIL MOISTURE DERIVED FROM IR ULTRASPECTRAL MEASUREMENTS}

Soil moisture estimation with IR land emissivity retrieved from satellite-measured IR radiances was previously addressed and here we briefly describe the concept communicated in the work of Zhou et al. [17]. The emissivity retrieved from satellite-measured IR radiance is an effective emissivity within the satellite instrument FOV, corresponding to a linear combination of pure scene types [18,22,23]. An effective surface emissivity can be written as a linear combination of water emissivity and non-water (or dry) emissivity; the soil moisture is a function of a total effective land emissivity and a nonwater or so-called pseudo dry-emissivity. This pseudo dry-emissivity is related to surface conditions (e.g., surface temperature, soil texture, and vegetation coverage) at a certain time and location.

A pseudo dry-emissivity can be derived from a land surface model or realistic climatology from historical measurements of surface emissivity and soil moisture. Since $0.25^{\circ}$ spatially-gridded monthly-mean datasets for IR emissivity and MW soil moisture climatology from satellite measurements are available, two climatology datasets were used to derive pseudo dry-emissivity; they are the global Essential Climate Variables (ECV) soil moisture dataset [7,23,24] from November 1978 to December 2015, and the IASI emissivity atlas [18] from June 2007 to May 2016. Emissivity at $1240 \mathrm{~cm}^{-1}$ is used since this spectral location has a significant emissivity sensitivity to surface water content variations [26]; however, emissivity at another comparable frequency could be used as well. Hereafter the emissivity refers to a real total emissivity at $1240 \mathrm{~cm}^{-1}$.

It is noted that pseudo dry-emissivity varies from location to location and time to time as the non-moisture related surface condition (e.g., soil texture, temperature, and vegetation cover) changes. To account for that variation, a pseudo dry-emissivity was currently computed with a monthly-mean spatial-grid of $0.25^{\circ}$ latitude-longitude. It is also noted that the absolute scaling constraint is included herein since the climatological data of MW-VSM and IR emissivity were used. This controls absolute scaling of the IR results, but allows IR-VSM to characterize geophysical field spatial and temporal variability from the observed IR emissivity. Details of the methodology for IR-VSM estimation and discussion on its sensitivity to emissivity and pseudo dry-emissivity are found elsewhere [17].

\section{IR-VSM EVALUATION}

IR- and MW-VSM are not expected to be the same since IR-VSM variation is dependent on IR emissivity. The IRVSM presented herein captures soil moisture variability but not the absolute value; the absolute accuracy depends on the accuracies of both emissivity and pseudo dry-emissivity. Detailed discussion with examples on geophysical field spatial and temporal variability of IR-VSM have been given to show a positive agreement with MW-VSM. The comparison between IR-VSM and MW-VSM in a statistical sense for global coverage over the period from June 2007 to December 2015 have been made; the coefficient of determination $\left(\mathrm{R}^{2}\right)$ and the standard deviation error (STDE) during this period, over the globe, were calculated to be about 0.850 and $0.032\left(\mathrm{~m}^{3} / \mathrm{m}^{3}\right)$, respectively [17]. In another example, a monthly-mean $0.25^{\circ}$ lat.-long. grid assembled IR-VSM is compared with MW-VSM as shown in Figure 1 for the same region of Northern America for July 2014. Comparison results $\mathrm{R}^{2}$ and STDE are 0.890 and $0.025\left(\mathrm{~m}^{3} / \mathrm{m}^{3}\right)$, respectively, showing how well MW- and IR-VSM compared in a spatial domain. We are mindful that some differences between IR- and MW-VSM are inevitable due to the nature of the different sensor/spectral band characteristics (e.g., the effective depth of a measurement). Since the same MW-VSM climatology employed to derive 
pseudo dry-emissivity was used in this analysis, an overall bias between IR- and MW-VSM is automatically corrected, but its $\mathrm{R}^{2}$ and STDE can definitely be utilized as a part of validation. This provides an assurance that IR-VSM is able to characterize geophysical field spatial and temporal variability.
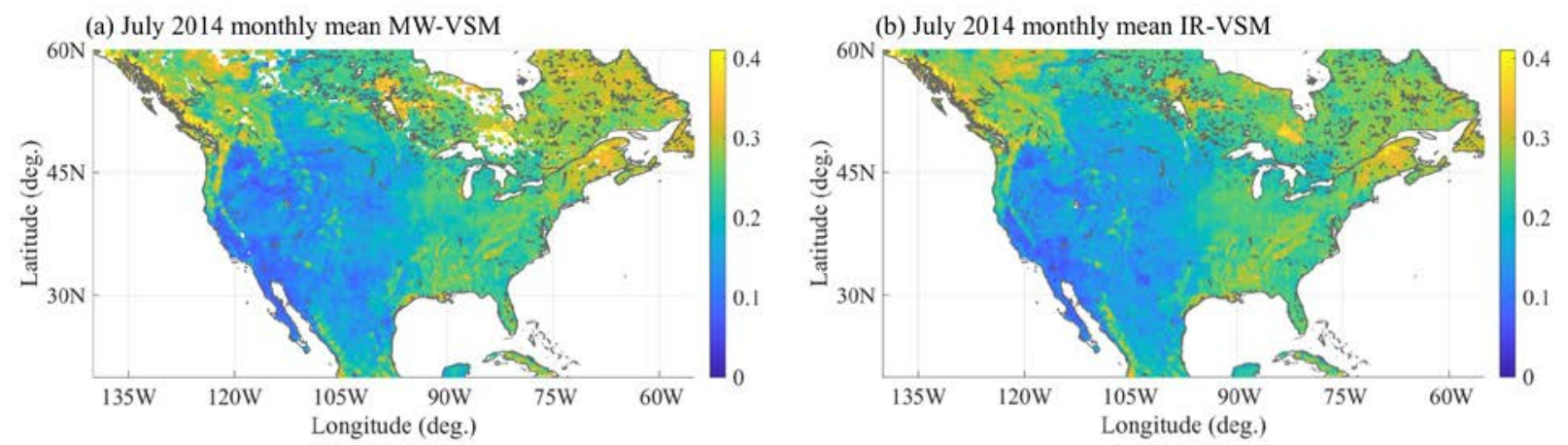

(c) Difference between (a) and (b)

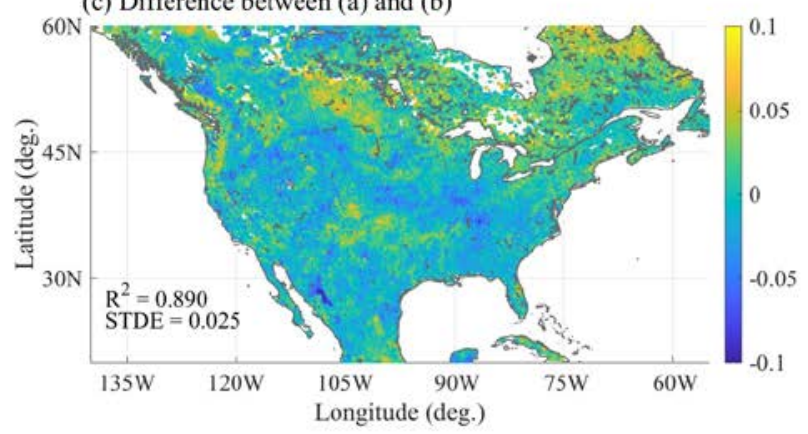

Figure 1. July 2014 monthly-mean: (a) MW-VSM, (b) IR-VSM, and (c) the difference between MWand IR-VSM in $\left(\mathrm{m}^{3} / \mathrm{m}^{3}\right)$. The $\mathrm{R}^{2}$ and STDE in $\left(\mathrm{m}^{3} / \mathrm{m}^{3}\right)$ indicated are from the plotted area of the figure.

A decade long IR-VSM data record is used to examine IR-VSM seasonal-cycle and inter-annual variations by intercomparing them with those of MW-VSM. Analysis based on monthly-mean time series is performed over a specific location, for example, Figure 2 plots VSM, co-located with a ground in-situ station in Milford, Utah $\left(38.34^{\circ} \mathrm{N}\right.$, $113.01^{\circ} \mathrm{W}$ ), showing its inter-annual variation captured by both MW- and IR-VSM; $\mathrm{R}^{2}$ and STDE data shown in the plot are from the overlapping period from June 2007 to December 2016. To clearly show the inter-annual variation, Figure 2b plots VSM for the month of September only (i.e., any random month can be selected for this demonstration) to explain its inter-annual variation for clarity. These seasonal-cycle and inter-annual variations may or may not be obvious, depending on the nature of the land properties. For this case, VSM inter-annual variation is clearly evident, although its inter-annual variation is small, it is noticeable in Figure $2 \mathrm{~b}$ (e.g., difference between the September of 2009 and 2014). Similar plots from Table Mountain, Montana $\left(45.80^{\circ} \mathrm{N}, 111.59^{\circ} \mathrm{W}\right)$ are shown in Figures $2 \mathrm{a}$ and $2 \mathrm{~b}$. More samples can be found elsewhere [17].

In order to evaluate the absolute value of IR-VSM, independent data sources are needed. They can be satellite measurement derived and/or ground in-situ direct measurements. An ideal dataset of VSM with a similar spatial and temporal resolution and a similar effective depth of measurements is desired. Here we have chosen ground in-situ soil moisture measurements from the SCAN network [19] administered by the United States Department of Agriculture (USDA) Natural Resources Conservation Service (NRCS). These ground stations are within the CONUS. Monthlyaveraged VSM data are available for a decade measurement history or longer. It is worth pointing out that in-situ measured VSM and satellite infrared measurement inferred IR-VSM are not the same naturally. For example, in-situ VSM is a point measured at a specific location of that station, and IR-VSM is averaged over $0.25^{\circ}$ latitude-longitude (i.e., an area with a diameter of $25 \mathrm{~km}$ ). Also, an in-situ VSM is measured at a certain depth, while an averaged IRVSM might be close to near-surface $(0-5 \mathrm{~cm})$ effective depth dependent on surface type. In addition to the difference between satellite remotely sensed and in-situ direct measured VSM, a large difference would exist if the field is not uniform in the field of regard of satellite measurements. We are mindful that the inter-comparison between in-situ 
measured and satellite derived VSM cannot be precisely used as a rigorous validation but rather an evaluation providing some kind of confidence on IR-VSM accuracy.

(a)

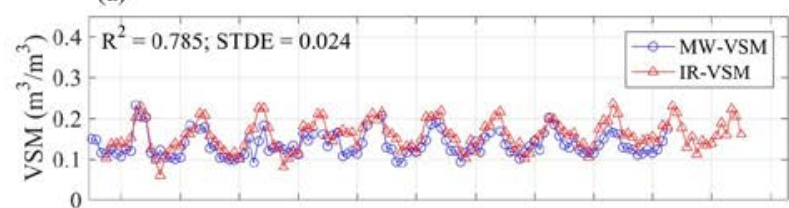

(b)

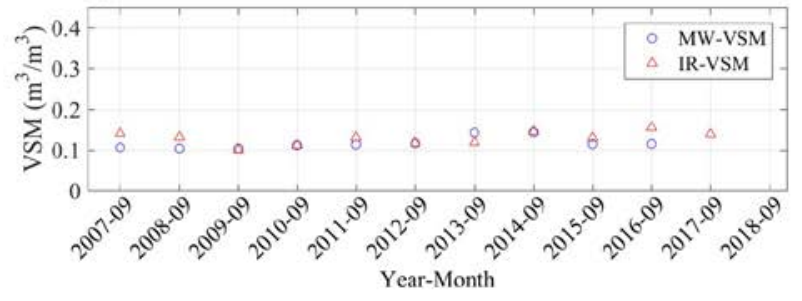

(c)

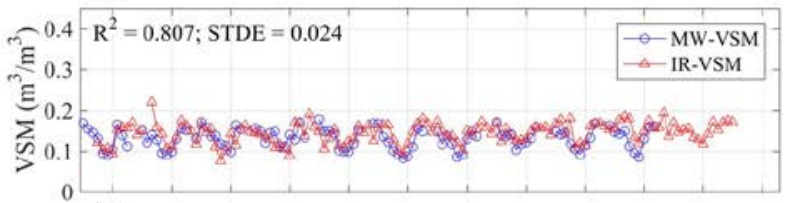

(d)

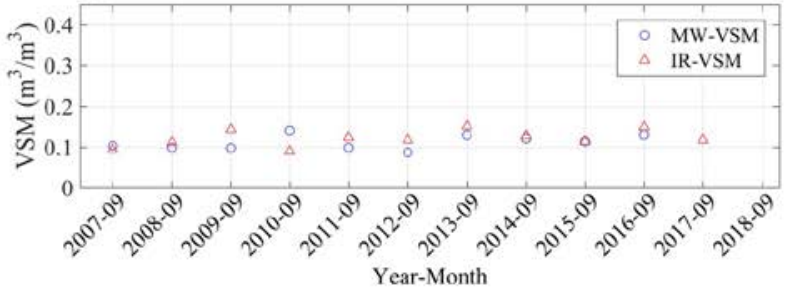

Figure 2. (a) Monthly-mean MW- and IR-VSM and (b) September samples from Milford, UT; similarly, (c) and (d) from Table Mountain, MT. $\mathrm{R}^{2}$ and STDE data shown in the plot are from the overlapping period of June 2007 to December 2016.

The two datasets, in-situ VSM and satellite IR-VSM, are fundamentally different; the ground in-situ VSM measurements are perhaps more accurate than satellite estimated IR-VSM but they are limited to the ground stations. Satellite measurements have a global coverage but VSM cannot be derived where the soil is frozen or the surface contains too much surface water (e.g., coastal areas). Currently there are 219 stations on the NCRS SCAN network providing data, of which 119 stations started collecting data about 10 years ago or earlier and have a common period of satellite IR-VSM data available at the locations of these in-situ stations. The monthly-mean VSM data from these 119 stations are statistically useful for inter-comparison with satellite derived IR-VSM, and presented herein.

Our analysis is based on a monthly-mean time series over each in-situ station over the past decade. For example, Figure 3 plots the inter-comparison between in-situ VSM and satellite derived IR-VSM at the 2 in-situ stations of Milford, UT and Table Mountain, MT. The IR-VSM variation is somewhat steady in comparison with that of in-situ VSM; this may be caused by a spatial coverage difference. Satellite derived IR-VSM is the mean of an area of a 25$\mathrm{km}$ diameter, making its variation smoother than that of ground in-situ VSM. So, the correlation between in-situ VSM and IR-VSM is not as good as that shown between MW- and IR-VSM (i.e., Figure 2). Nevertheless, the bias between in-situ VSM and satellite IR-VSM, over the past decade (2007-2017), is critical to this evaluation as the measurements are truly independent.

(a)

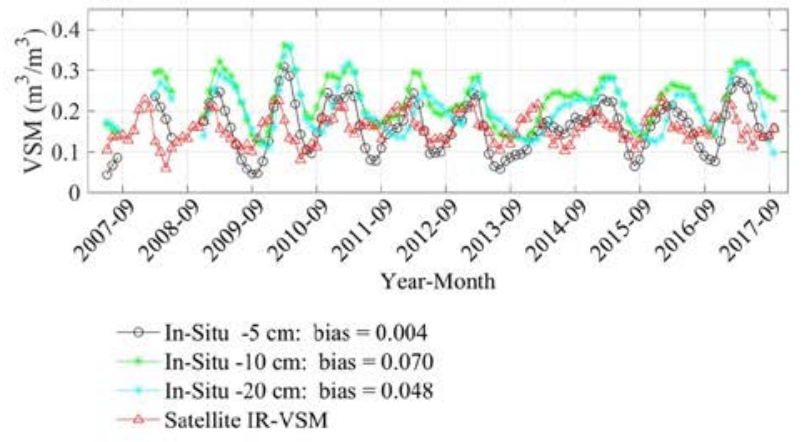

(b)

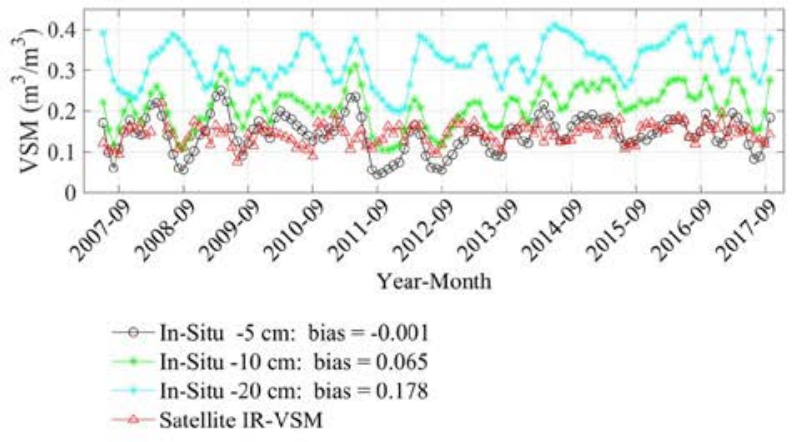

Figure 3. (a) Monthly-mean IR-VSM vs. in-situ VSM at three different measurement depths: (a) From Milford, UT $\left(38.34^{\circ} \mathrm{N}, 113.01^{\circ} \mathrm{W}\right)$; and (b) from Table Mountain, MT $\left(45.80^{\circ} \mathrm{N}, 111.59^{\circ} \mathrm{W}\right)$. 
Ground in-situ measurements provide soil moisture data at several different measurement depths, usually at $-5,-10$, $20 \mathrm{~cm}$ and so on, here we plotted the in-situ VSM at three different measurement depths and compare them to satellite IR-VSM. The soil moisture measured at different depths under the surface can be dramatically different, depending on the location of the in-situ station. Usually, a minimum bias between satellite IR-VSM and in-situ VSM at $5 \mathrm{~cm}$ under the surface appears, as shown for example in Figure 3. This is expected as IR-VSM is converted from associated surface emissivity. The IR-VSM should be at surface or near surface $(0-5 \mathrm{~cm})$ but an effective depth is uncertain. So a significant source of error could be introduced simply by comparing such inherently different observations, i.e. using in-situ VSM to evaluate satellite IR-VSM. When the inter-comparison between in-situ VSM and satellite IR-VSM are conducted here, we choose the in-situ VSM with a minimum bias from IR-VSM for statistical analysis. As shown in the two examples in Figure 3, in-situ data at a measurement depth of $-5 \mathrm{~cm}$ are used for both cases.

Since there are major differences in the measurement methodology and geophysical location coverage between these two VSM datasets, a relatively large bias could exist depending on the individual location of the ground in-situ station, shown in Figure 3, for instance. A realistic question is how well a point in-situ measured VSM can represent a large field of regard of satellite IR-VSM (area with a 25-km diameter for our cases). It might not be very meaningful to evaluate IR-VSM with ground in-situ VSM over a specific ground station but rather to do so over a large number of ground stations to compensate the error from an individual comparison over a ground station. In summary, Figure 4 plots the bias and STDE, between two datasets of in-situ VSM and IR-VSM, from 114 stations. The 5 out of 119 stations have their bias greater than $0.1\left(\mathrm{~m}^{3} / \mathrm{m}^{3}\right)$ and have been considered as outliers plotted in open cycles. From these 114 stations, an overall mean bias is $0.005\left(\mathrm{~m}^{3} / \mathrm{m}^{3}\right)$, a STDE is $0.066\left(\mathrm{~m}^{3} / \mathrm{m}^{3}\right)$, and $\mathrm{R}^{2}$ is 0.714 . These two datasets are reasonably similar considering their physical measurement differences. It is noticed that similar biases exist between MW-VSM and in-situ VSM; for instance, the plots shown in Figures 2 and 3. The same analysis based on a monthly-mean time series has been done between satellite MW-VSM and in-situ VSM over a period of 9 years (20072016). The results, plotted in Figure 5, are comparable with those plotted in Figure 4 with some small differences that might be due to the difference of time coverage.

(a)

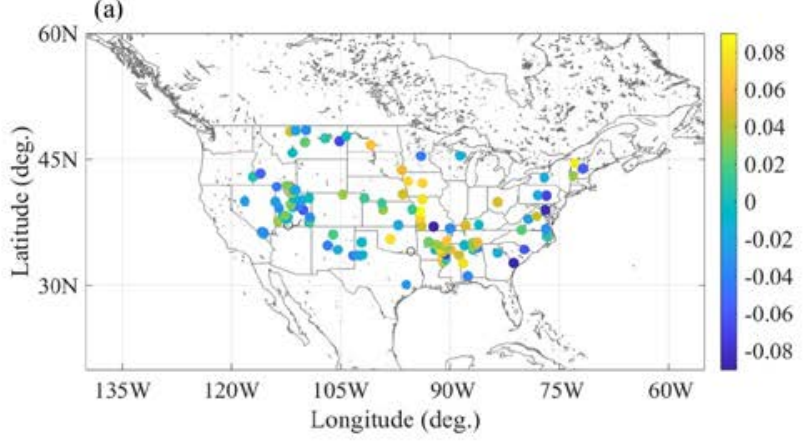

(b)

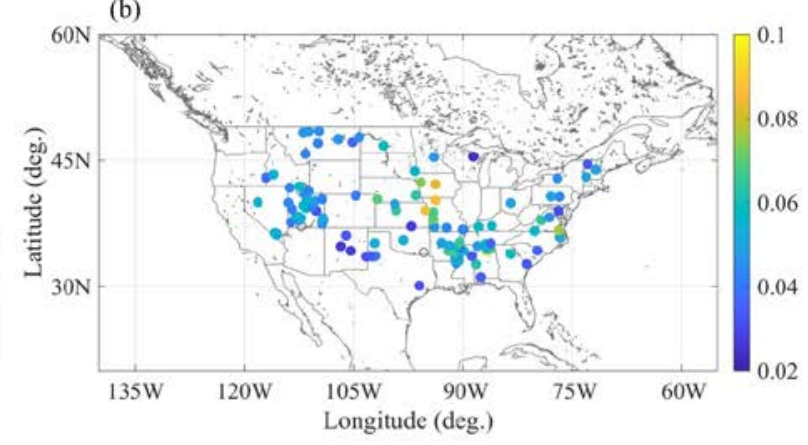

Figure 4. Inter-comparison between monthly-mean in-situ VSM and satellite IR-VSM: statistical parameters (a) bias and (b) STDE $\left(\mathrm{m}^{3} / \mathrm{m}^{3}\right)$ over the past decade (2007-2017).


Figure 5. Same as Figure 4 but the inter-comparison between monthly-mean in-situ VSM and satellite MW-VSM over the period of 2007-2016. 
Figure 6 plots the biases and STDE of individual stations, having in-situ VSM compared with IR-VSM and MWVSM. The biases between IR-VSM and in-situ VSM and the biases between MW-VSM and in-situ VSM are very similar as expected since the IR and MW VSM are not independent. A very small difference between the mean biases of IR- and MW-VSM in reference to in-situ VSM might be due to the difference of the time coverage of 2007-2017 and 2007-2016, respectively. We believe that the physical differences, caused by measurement methodology and geophysical location coverage involved in the biases of individual stations, can be limited in a mean bias of all these inter-comparisons. A conclusion can be drawn, from the mean bias of $0.005 \mathrm{~m}^{3} / \mathrm{m}^{3}$ from 114 ground stations, that absolute values of IR-VSM are corresponding to in-situ VSM given the inherently different observations. As these insitu stations are within the CONUS, the inter-comparison results shown herein may not represent IR-VSM evaluation over a global coverage but rather over the locations of ground in-situ stations within the CONUS.

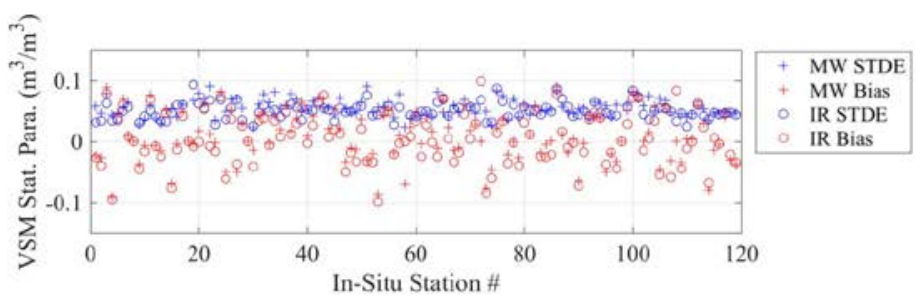

Figure 6. Bias (in red) and STDE (in blue) between IR-VSM and in-situ VSM (in cycle), and between MW-VSM and in-situ VSM (in cross).

\section{CONCLUSIONS}

The investigation into the relationship between IR-VSM and infrared land surface emissivity from a global perspective as inferred from advanced satellite sounder data was recently reported [17]. It demonstrated that IR-VSM variation is consistent with MW-VSM using an 8-year period of overlapping satellite data of MW and IR observations. However, since the key parameter pseudo dry-emissivity climatology was generated by using the same MW-VSM climatology, the IR-VSM cannot be evaluated by MW-VSM in a sense of absolute accuracy which depends on the accuracies of both emissivity and pseudo dry-emissivity. Here, a large set of independent ground in-situ soil moisture measurements is used to evaluate IR-VSM absolute accuracy, as well as its variability. Monthly-mean data used from the last decade of a total of 114 in-situ stations for inter-comparison, show that the mean bias between in-situ VSM and satellite IRVSM is $0.005\left(\mathrm{~m}^{3} / \mathrm{m}^{3}\right)$. Despite the physical differences of ground in-situ and satellite measurements, the absolute accuracy of IR-VSM is evaluated over the CONUS by independent ground in-situ soil moisture measurements. The mean bias between in-situ VSM and satellite IR-VSM estimated herein is small enough to indicate that the absolute values of IR-VSM, as well as MW-VSM, are reasonably accurate relative to in-situ observations.

This initial IR-VSM evaluation is part of our evaluation effort for IR-VSM. Our future work in this area will continue evaluating IR-VSM using in-situ soil moisture data from the International Soil Moisture Network [27], and using other satellite measurements such as the Soil Moisture Active Passive (SMAP) [28]. In addition to our IR-VSM evaluation efforts, both IR-VSM and emissivity will be routinely derived using IASI single-footprint measurements from MetOp IASI with a desired higher-temporal-resolution (e.g., a weekly resolution) climatological database of pseudo dryemissivity.

Acknowledgements. This work, including the land surface emissivity retrieval algorithm and soil moisture estimation, was performed under the NAST-I program supported by NASA Headquarters and NASA Langley Research Center. IASI was developed and built under the responsibility of the Centre National d'Etudes Spatiales (CNES). It is flown aboard the MetOp-A satellite as part of the EUMETSAT Polar System. The IASI L1C data are received through NOAA Comprehensive Large Array-data Stewardship System (CLASS). The ESA CCI Surface Soil Moisture Product (i.e., MW-VSM) was downloaded from ESA CCI Soil Moisture website. The in-situ soil moisture data were obtained from the Soil Climate Analysis Network (SCAN). The authors wish to specifically acknowledge Dr. Jack Kaye of NASA’s Science Mission Directorate for his continued, enabling support of the NAST-I program. 


\section{REFERENCES}

[1] Z. Li, B. Tang, H. Wu, H. Ren, G. Yan, Z. Wan, I. F. Trigo, and J. A. Sobrino, "Satellite-derived land surface temperature: Current status and perspectives,” Remote Sens. Environ., 131, 14-37 (2013).

[2] A. G. Turner and H. Annamalai, "Climate change and the South Asian Monsoon," Nature Climate Change, 2, 587-595 (2012).

[3] S. I. Seneviratne, T. Corti, E. L. Davin, M. Hirschi, E. B. Jaeger, I. Lehner, B. Orlowshy, and A. I. Teuling, "Investigating soil moisture-climate interactions in a changing climate: A review," Earth-Science Reviews, 99, 125-161 (2010).

[4] R. H. Reichle, R. D. Koster, J. Dong, and A. A. Berg, "Global soil moisture from satellite observations, land surface models, and ground data: implications for data assimilation," Journal of Hydrometeorology, 5, 430442 (2003).

[5] Y. Fan and H. van den Dool, "Climate Prediction Center global monthly soil moisture data set at $0.5^{\circ}$ resolution for 1948 to present,” Journal of Geophysical Research, 109, D10102 (2004).

[6] L. Wang and J. J. Qu, "Satellite remote sensing applications for surface soil moisture monitoring: A review," Frontiers of Earth Science in China, 3(2), 237-247 (2009).

[7] M. Owe, R. de Jeu, and T. Holmes, "Multisensor historical climatology of satellite-derived global land surface moisture," Journal of Geophysical Research, 113, F01002 (2008).

[8] W. W. Verstraeten, F. Veroustraete, C. J. van der Sande, I. Grootaers, and J. Feyen, "Soil moisture retrieval using thermal inertia, determine with visible and thermal spaceborne data, validated for European forests," Remote Sens. Environ., 101(3), 299-314 (2006).

[9] T. N. Carlson, R. R. Gillies, and E. M. Perry, "A method to make use of thermal infrared temperature and NDVI measurements to infer surface soil water content and fractional vegetation cover," Remote Sensing Reviews, 9(1), 161-173 (2009).

[10] M. Urai, T. Matsunaga, and T. Ishii, "Relationship between soil moisture content and thermal infrared emissivity of the sand sampled in Muus Desert China,” Remote Sensing Society of Japan, 17(4), 322-331 (1997).

[11] K. Ogawa, T. J. Schmugge, and S. Rokugawa, "Observations of the dependence of the thermal infrared emissivity on soil moisture,” Geophysical Research Abstracts, 8, 04996 (2006).

[12] M. Mira, E. Valor, V. Caselles, E. Rubio, C. Coll, J. M. Galve, R. Niclòs, J. M. Sánchez, and R. Boluda, "Soil moisture effect on thermal infrared (8-13 $\mu \mathrm{m})$ emissivity," IEEE Transactions on Geoscience and Remote Sensing, 48(5), 2251-2260 (2010).

[13] V. Garcia-Santos, E. Valor, V. Caselles, C. Coll, and M. A. Burgos, "Effect of soil moisture on the angular variation of thermal infrared emissivity of inorganic soils," IEEE Geoscience and Remote Sensing Letters, 11(6), 1091-1095 (2014).

[14] D. Blumstein, G. Chalon, T. Carlier, C. Buil, P. Hebert, T. Maciaszek, G. Ponce, and T. Phulpin, "IASI instrument: technical overview and measured performances," SPIE Proceedings, 5543, 196-207 (2004).

[15] D. K. Klaes, M. Cohen, Y. Buhler, P. Schlüssel, R. Munro, J.-P. Luntama, A. von Engeln, E. Ó. Clerigh, H. Bonekamp, J. Ackermann, and J. Schmetz, “An introduction to the EUMETSAT Polar System,” Bulletin of the American Meteorological Society, 88, 1085-1096 (2007).

[16] F. Hilton et al, "Hyperspectral Earth Observation from IASI: five years of accomplishments," Bulletin of the American Meteorological Society, 93, 347-370 (2012).

[17] D. K. Zhou, A. M. Larar, and X. Liu, "On the relationship between land surface infrared emissivity and soil moisture,” J. Appl. Remote Sens., 12(1), 016030 (2018).

[18] D. K. Zhou, A. M. Larar, X. Liu, W. L. Smith, L. L. Strow, P. Yang, P. Schlüssel, and X. Calbet, "Global land surface emissivity retrieved from satellite ultraspectral IR measurements," IEEE Transactions on Geoscience and Remote Sensing, 49(4), 1277-1290 (2011).

[19] G. L. Schaefer and R. F. Raetzold, "SNOTEL (SNOwpack TELemetry) and SCAN (Soil Climate Analysis Network)," Proceedings of an International Workshop on Automated Weather Stations for Applications in Agriculture and Water Resources Management, High Plains Climate Center, University of Nebraska-Lincoln, USA and the World Meteorological Organization (WMO), AGM-3 WMO/TD No. 1074 (2001).

[20] C. Prigent, F. Aires, W. B. Rossow, and A. Robock, "Sensitivity of satellite microwave and infrared observations to soil moisture at a global scale: Relationship of satellite observation to in situ soil moisture measurements," J. Geophy. Res., 110, D07110 (2005). 
[21] C. Albergel et al., "Evaluation of remotely sensed and modelled soil moisture products using global groundvased in situ observations," Remote Sens. Environ., 118, 215-226 (2012).

[22] E. Valor and V. Caselles, "Mapping land surface emissivity from NDVI: application to European, African, and South American areas," Remote Sens. Environ., 57(3), 167-184 (1996).

[23] G. C. Hulley, S. J. Hook, E. Manning, S.-Y. Lee, and E. Fetzer, "Validation of the Atmospheric Infrared Sounder (AIRS) version 5 land surface emissivity product over Namib and Kalahari deserts," Journal of Geophysical Research, 114, 9104.1-9104.11 (2009).

[24] Y. Y. Liu, R. M. Parinussa, W. A. Dorigo, R. A. M. de Jeu, W. Wagner, A. I. J. M. van Dijk, M. F. McCabe, and J. P. Evans, "Developing an improved soil moisture dataset by blending passive and active microwave satellite-based retrievals,” Hydrology Earth System Science, 15(2), 425-436 (2011).

[25] Y. Y. Liu, W. A. Dorigo, R. M. Parinussa, R. A. M. de Jeu, W. Wagner, M. F. McCabe, J. P. Evans, and A. I. J. M. van Dijk, "Trend-preserving blending of passive and active microwave soil moisture retrievals," Remote Sens. Environ., 123, 280-297 (2012).

[26] J. W. Salisbury and D. M. D’Aria, "Emissivity of terrestrial material in the 8-14 $\mu \mathrm{m}$ atmospheric window," Remote Sens. Environ., 42, 83-106 (1992).

[27] A. Robock, K. Y. Vinnikov, G. Srinivasan, J. K. Entin, S. E. Hollinger, N. A. Speranskaya, S. Liu, and A. Namkhai, “The global soil moisture data bank,” Bull. Amer. Meteor. Soc., 81, 1281-1299 (2000).

[28] D. Entekhabi, E. Njoku, P. O’Neill, M. Spencer, T. Jackson, J. Entin, E. Im, and K. Kellogg, "The soil moisture active passive (SMAP) mission,” Proceedings of the IEEE, 98(5), 704-716 (2010). 